\title{
RISCOS OCUPACIONAIS: PERCEPÇÃO DE ENFERMEIROS DE UM HOSPITAL PÚBLICO
}

\section{OCCUPATIONAL HAZARD: PERCEPTION OF THE NURSES ON A PUBLIC HOSPITAL}

\author{
Jarbas Willian Paiva Leite*, Giovana Fernandes Araujo**
}

Autor para correspondência: Jarbas Willian Paiva Leite - jarbaswilliam_@hotmail.com

* Discente do curso de enfermagem da FAINOR, Vitória da Conquista, Bahia

**Docente do curso de enfermagem da FAINOR, Vitória da Conquista, Bahia

\section{R E S U M O}

Este estudo teve por objetivo avaliar a percepção dos enfermeiros quanto aos riscos ocupacionais existentes nas unidades de clínicas médica e cirúrgica de um hospital público. Trata-se de um estudo exploratório-descritivo, de natureza qualitativa, realizado em um hospital público, de grande porte, localizado em um município do Sudoeste da Bahia. A população foi composta por 11 enfermeiros que atuam nos períodos matutino e vespertino nas unidades de clínica médica e cirúrgica. A pesquisa foi realizada no período de 01 a 30 de março de 2016, através de entrevista gravada utilizando-se um roteiro semiestruturado elaborado e aplicado pelo pesquisador, individualmente, no local de trabalho, em horário previamente determinado com os participantes. Os dados foram analisados visando à identificação das categorias e unidades temáticas a partir da utilização do referencial de Bardin. A partir da análise das respostas emergiram três categorias, a saber: 1 - concepção de riscos ocupacionais; 2- Riscos percebidos no ambiente de trabalho e 3 -Medidas de prevenção de acidentes e adoecimentos utilizadas no ambiente de trabalho. $O$ foco dos entrevistados, quanto aos riscos ocupacionais, é o risco biológico e, consequentemente, o uso de EPI para este risco é a medida de prevenção mais utilizada. Conclui-se que há a necessidade da educação permanente a respeito de todos os riscos ocupacionais existentes no ambiente de trabalho, bem como a sensibilização da instituição quanto às dificuldades vivenciadas por esses profissionais relacionadas à sobrecarga de trabalho e aos recursos materiais.

PALAVRAS-CHAVE: Riscos Ocupacionais, Enfermagem. 
This study aimed to assess the nurses' perception of the existing occupational hazards in the medical and surgical clinical units of a public hospital. This is an exploratory-descriptive study, of a qualitative nature, conducted in a large public hospital located in a municipality of the southwestern region of Bahia. The population consisted of 11 nurses working in the morning and in the afternoon in the medical and surgical units, totalizing 11 participants. The survey was conducted from 01 to March 302016 through recorded interviews using a semi-structured script, elaborated and applied by the researcher. The interviews took place individually, in the workplace, in the time previously determined by the mentioned professionals. The data were analyzed in order to identify the categories and the thematic units from Bardin's methodological referential. From the analysis of the responses emerged three categories, namely: 1 - Conception of occupational hazards; 2 - Risks perceived in the workplace and 3 - Prevention actions for accident and illnesses in the workplace. Regarding the occupational hazards, the focus of the interviewed were the biological risk, and, consequently, the use of PPE for this risk was the preventive action most widely employed. We conclude that ongoing education is needed regarding all existing occupational hazards in the working environment. The institution must be made aware about the difficulties experienced by these professionals related to the overload of work and to the material resources.

KEYWORDS: occupational hazards, Nursing. 


\section{INTRODUÇÃO}

Os riscos ocupacionais são considerados eventos no âmbito trabalhista, seja individualmente ou por condições da instituição, que possam gerar algum dano a saúde do trabalhador, provocando a morte ou adoecimento'.

Os hospitais são locais com vasta quantidade de riscos, os quais podem sofrer variações devido a sua natureza, como os biológicos, físicos, químicos, ergonômicos e psicossociais, que afetam drasticamente a saúde do profissional de saúde em função do tempo de exposição e a intensidade do risco ${ }^{2}$.

Dentre as condições que contribuem para a ocorrência de acidentes e doenças ocupacionais, entre profissionais de enfermagem, se destacam o ambiente penoso e insalubre, falta de condições ideais para prestação de serviço de qualidade, precarização do trabalho, excesso de funções, carga horária extensa e a má remuneração ${ }^{3}$.

A busca por uma melhor condição de vida faz com que os profissionais se comprometam com suas atividades laborais além do que seu corpo suporta, onde a sua saúde não é colocada em primeiro lugar, somente buscando a realização de várias atividades diariamente, estando em vários momentos exaustos das suas rotinas trabalhistas, expondo-se a qualquer ambiente de trabalho, carregando como consequência o desgaste físico e mental.

É nesse cenário propício ao surgimento de acidentes de trabalho e doenças ocupacionais que se insere os profissionais de enfermagem ${ }^{4}$, compondo uma equipe eminentemente feminina, pois além das atividades exercidas no trabalho existem aquelas domésticas, que aumenta as chances de adoecimento ${ }^{5}$ torna-se mais vulnerável.

Uma das características dos profissionais de enfermagem é a não priorização do cuidar da sua própria saúde, pois, encontram-se constantemente inseridos em vários vínculos e em locais insalubres, com condições inadequadas de desenvolver seu trabalho, com execução mecânica e repetitiva das atividades, de maneira a comprometer no momento que dedicam para $\circ$ autocuidado e a ponto de subestimarem os riscos inerentes ao trabalho ${ }^{6}$.

A busca de medidas eficazes para a segurança dos profissionais de enfermagem se faz necessário, principalmente no tocante aos fatores de risco, os quais se encontram constantemente expostos durante o seu labor, com isso poderá surgir reduções no número de acidentes decorrentes do trabalho, favorecendo a redução de gastos institucionais para a previdência social, como também melhores condições de saúde para os trabalhadores ${ }^{7}$.

Este estudo propõe como objetivo avaliar a percepção dos enfermeiros quanto aos riscos ocupacionais existente nas unidades de clínica médica e cirúrgica de um hospital público.

\section{METODOLOGIA}

Trata-se de um estudo descritivo-exploratório de abordagem qualitativa. A coleta foi realizada em março de 2016 através de um roteiro semiestruturado em um hospital de grande porte localizado em um município do sudoeste da Bahia.

A amostra foi constituída por 11 enfermeiros que atuam nas unidades de clínica médica e cirúrgica nos turnos matutino e vespertino e que aceitaram participar voluntariamente da pesquisa e assinaram - Termo de Consentimento Livre e esclarecido, excluídos aqueles profissionais enfermeiros que estavam de licença ou afastados do trabalho no momento da coleta.

A coleta se deu através de forma individual e gravada utilizando-se um roteiro semi-estruturado elaborado e aplicado pelo pesquisador no local de trabalho em horário previamente determinado junto aos profissionais mencionados. Os mesmos foram orientados quanto ao objetivo da pesquisa e o pesquisador continuou a disposição para esclarecer qualquer dúvida. O fechamento amostral ocorreu no momento em que houve uma repetição na fala dos informantes.

As entrevistas, após serem realizadas, foram transcritas para o programa Word/Starter 2010. Os dados foram analisados visando a identificação 
das categorias e unidades temáticas a partir da utilização do referencial de Bardin, que institui: uma primeira leitura flutuante e aprofundada dos dados grifando os relatos significativos, semelhantes e diferentes; recortes de fragmentos grifados; busca a partir das temáticas mencionadas no objetivo; elaboração de uma lista de fala dos entrevistados por categorias; escolha das falas que possuem maior poder de síntese e abrangência, informações dentre os conteúdos das entrevistas para exemplificar as categorias emergentes. A análise foi ancorada no referencial teórico escolhido.

O presente estudo foi aprovado pelo comitê de ética e pesquisa da Faculdade Independente do Nordeste - FAINOR, sob parecer $n^{\circ} 1.415 .034$ resguardado pela Resolução 466/12 referente a pesquisas com seres humanos, resguardando a autonomia, sigilo e anonimato foram preservados.

\section{RESULTADOS E DISCUSSÕES}

Da amostra dos 11 profissionais enfermeiros, 09 são do gênero feminino e 02 do gênero masculino, na faixa etária de 31 a 45 anos. Em relação ao tempo de trabalho na instituição variou entre 02 a 07 anos e quando questionados sobre o período de formação acadêmica este foi de 06 a 16 anos.

A partir da análise das respostas emergiram três categorias, a saber: 1 - Concepção de riscos ocupacionais; 2- Riscos percebidos no ambiente de trabalho e 3 - Medidas de prevenção de acidentes e adoecimentos utilizadas no ambiente de trabalho.

\section{CONCEPÇÃO DE RISCOS OCUPACIONAIS}

Nesta categoria observa-se que os participantes do estudo definiram "riscos ocupacionais" como tudo aquilo que possa causar danos à saúde do trabalhador, principalmente à física e mental, no exercício de suas atividades, conforme os seguintes discursos:
São atividades no exercício profissional que podem desencadear doenças ocupacionais (E1).

[...] Se expor à situações que podem trazer prejuízo pra pessoa ehh..., como físico, emocional ou social (E3).

Tudo e qualquer situação vivenciada pelo trabalhador que possa colocá-lo sob risco a sua saúde a sua integridade física, psíquica e emocional (E4).

Eu entendo que os riscos ocupacionais é tudo aquilo que consegue potencializar a condição de acidentes ou do profissional ou próprio paciente (E8).

Os riscos ocupacionais estão relacionados a qualquer intimidação na integridade física ou psíquica dos profissionais, relacionados a um desencaminhamento das atividades de trabalho que se considera como normal, por menor que seja essa mudança ${ }^{2}$.

Considerando os depoimentos infere-se que os depoentes possuem conhecimento adequado sobre os riscos ocupacionais, algo que favorece bastante a intermediação dos gestores no intuito de potencializar a eficiência das ações desenvolvidas por esses profissionais durante a sua prática, com a qualificação dos mesmos por meio de treinamentos e normas que são elaboradas por órgãos competes.

O conhecimento do que são riscos ocupacionais é o primeiro passo para a prevenção de acidentes de trabalho. Importante lembrar que o Ministério do Trabalho e Emprego (MTE) elaborou normas regulamentadoras(NRs) com a finalidade estabelecer as diretrizes básicas para a implementação de medidas de proteção à segurança e à saúde dos trabalhadores dos serviços de saúde, sendo a NR 32 preparada para deliberar diretrizes referentes às condições de segurança, proteção e preservação da saúde dos profissionais que atuam em estabelecimentos de saúde ${ }^{8}$.

\section{RISCOS PERCEBIDOS NO AMBIENTE DE TRABALHO}


Os riscos ergonômicos e biológicos foram os únicos referidos pelos entrevistados. Foi possível inferir, através das falas dos entrevistados, que o risco mais preocupante para os mesmos é o biológico:

[...] E no caso os perfurocortantes né! Principalmente em relação aos pacientes né! De SIDA que o risco é bem... Tipo assim né! De você adquirir é bem mais fácil (E2).

Sim... ehh... Na Enfermagem existe o risco né! Assim mais grave que é o perfuro cortante né! Que o risco ocupacional principalmente na clínica médica, onde existe pacientes soro positivos, quer dizer é o que tem de maior prejuízo né! No caso são os acidentes perfurocortantes [...] (E3).

Principalmente aqui na clínica médica os riscos ocupacionais mais perceptíveis são risco com perfurocortante né! Aqui infelizmente algumas vezes os colegas de trabalho já se contaminaram com uma simples agulha de insulina no teste de glicemia capilar ou então mesmo com agulha no momento de uma punção [...] (E9).

Devido ao grande impacto que ocorre na esfera psicológica da população em relação a infecção pelo vírus da imunodeficiência adquirida (AIDS) faz com que os profissionais fiquem mais alerta, além disso surge a mídia como uma ferramenta que aborda essa patologia intensamente, a qual é sempre frisada por não haver cura, consequentemente se torna $\circ$ alvo das atenções, contudo outras doenças que as chances de infecção são maiores acabam sendo menos preocupantes no campo da saúde como as hepatites, esse esquecimento é fator de risco pra o aumento no índice dessas patologias.

Na prestação da assistência de enfermagem advém o risco de acidentes com materiais perfurocortantes já que os profissionais constantemente utilizam materiais como as agulhas, cateteres intravenosos, laminas e outros comuns a execução de sua prática ${ }^{11}$.

Esta exposição se caracteriza como ocorrência emergencial, pois, através desse contato podem ser transmitidos mais de 20 tipos de patologias, com ênfase ao vírus do HIV, hepatite B e C. A maioria dos trabalhadores apontaram o HIV, porém estudos mostram que a possibilidade de aquisição do vírus da imunodeficiência adquirida é menor em relação aos demais, onde corresponde a 0,3\% por exposição percutânea e 0,9\% por exposição nas mucosas, já a hepatite $B$ alcança os $40 \%$ por via percutânea e a hepatite $C$ equivale a $1,8 \%{ }^{12}$.

Observou-se que os participantes em nenhum momento citaram os riscos químicos e físicos. A equipe de enfermagem está exposta a riscos físicos como: ruídos de máquinas e aparelhos, manipulação de materiais que emitem energia como bisturi, inalador e aspirador e os químicos através da preparação de medicações ${ }^{2}$.

A não visualização para os outros tipos de riscos pode estar associada a mínima importância prestada, desde o aprendizado na academia até as capacitações e educação continuada nas instituições, as quais procuram uma abordagem praticamente e somente biológica, com isso não instigando os acadêmicos e profissionais a vislumbrarem esses outros perigos aos quais eles estão vivenciando continuamente, contribuindo assim para empregados com somente um foco em seu local de trabalho.

Alguns participantes do estudo demonstraram preocupação em relação ao contato com o paciente que está infectado com bactérias multirresistentes, colocando-o como um dos principais tipos de risco biológico no seu ambiente de trabalho:

[...] E também em relação a bactérias que muitos pacientes também aqui eh... adquirem bactérias multirresistentes levando no caso, levando riscos né! Até a questão do profissional também [...] (E2).

[...] Riscos de... Aquisição de bactérias multirresistentes [...] (E5).

[...] Contato devido a uma bactéria multirresistente $[\ldots]$ (E9).

Além do risco de adoecimento de maior contato com pacientes adoecidos e esses pacientes também tem mais probabilidade de adquirir alguma bactéria mais resistente [...] (E 17 1). 
As ocorrências de infecção nos profissionais por microrganismos multirresistentes podem estar associada a vários fatores, como o tempo prolongado dentro das unidades de saúde, o manuseio constante com os clientes e a falta de utilização das práticas de precaução padrão, fazendo com que se tornem portadores e disseminadores de várias patologias ${ }^{13}$.

Os discursos demonstram que alguns enfermeiros se sentem mais vulneráveis devido à precarização do trabalho relacionada aos recursos materiais existentes na unidade, classificando-os como insuficientes e deteriorados, o que gera uma assistência inadequada com maior chance de ocorrer um acidente de trabalho. Entre esses materiais foram citados os Equipamento de Proteção Individual (EPI) e insumos, conforme evidenciados nos seguintes discursos:

[...] Falta os equipamentos básicos de proteção individual né! Tem momentos que a gente tem todos os equipamentos, mas tem momento que a gente não tem né! por exemplo, as vezes com pacientes com tuberculose não tem a máscara N95, as vezes mascara comum, eh, as vezes a gente não tem um avental pra proteção né! e descartar logo após manipulação do paciente,eh.. em alguns momentos isso nos põe a um enorme risco de acidente biológico $[\ldots]$ (E4).

[...] Falta de recursos como falta de materiais de insumos que isso acaba levando a riscos ao funcionário ao servidor [...] (E10).

Diversas causas são apontadas como fatores colaboradores para o desenvolvimento dos acidentes de trabalho: a falta de estrutura adequada dos ambientes de trabalho; descuido; pressa; excesso de autoconfiança; escassez de qualificação para os funcionários; desconhecimento dos modos de prevenção; redução dos recursos humanos e materiais; carga horária em excesso; entre outros ${ }^{14}$.

Em maioria esmagadora das instituições públicas vivem o descaso, devido à falta de verbas destinadas a saúde, gerando a partir disso a não aquisição de materiais e insumos primordiais para a assistência, fazendo com que os profissionais procurem alternativas não adequadas para a concretização dos serviços, assim estando mais susceptíveis a aquisição de alguma disfunção na sua saúde.

Considera-se EPI todo dispositivo de uso individual destinado a proteger a saúde e a integridade física do trabalhador, sendo a empresa obrigada a fornecer aos empregados, sem custo, EPI adequado ao risco e em perfeito estado de conservação e funcionamento ${ }^{15}$.

A sobrecarga de trabalho e o estresse, que fazem parte do risco ergonômico, também foram citados como fatores de risco para acidentes de trabalho.

[...] muitas vezes tarefas e desvios de função que não compete a Enfermagem né! Vem sendo atribuídas aos Enfermeiros, gerando um estresse por conta do próprio paciente que se sente mal atendido, do Enfermeiro que não tem condição de atender aquela demanda né! A sobrecarga de trabalho né! Por ser uma quantidade enorme de pacientes né! [...] (E4).

[...] Riscos de adoecimentos de algumas patologias no campo psicológico né! Estresse, depressões, dentre outras provenientes de uma carga de trabalho excessiva (E5).

O estresse torna-se resultante da sobrecarga de trabalho dos profissionais, pois são obrigados a cumprir jornadas exorbitantes, seja por uma remuneração insuficiente ou por falta de planejamento na contratação da equipe, podendo também ser fruto de dimensionamento de pessoal realizado sem o conhecimento devido, o que poderá comprometer todo o trabalho de um grupo profissional, refletindo-se na esfera psicofisiológica.

A demanda das atividades laborais está relacionada aos fatores inerentes ao labor e ao local de execução das práticas trabalhistas, as quais atuam diretamente sobre o organismo do trabalhador, sendo a sobrecarga de trabalho um meio de interferência em alguns aspectos da sua saúde, seja no campo físico ou psíquico, decorrentes de uma elevada demanda de pacientes como também situações conflitantes ou uma carga horária exacerbada ${ }^{16}$. 
A NR 17, do MTE, institui diretrizes para aperfeiçoar as condições laborativas, a fim de gerar conforto aos trabalhadores, além de segurança e eficiência para a realização das suas atividades. Logo, para alcançar este objetivo, faz-se necessário que o trabalho seja adaptado às características físicas e psicofisiológicas dos trabalhadores ${ }^{17}$.

\section{MEDIDAS DE PREVENÇÃO DE ACIDENTES E ADOECIMENTOS UTILIZADAS NO AMBIENTE DE TRABALHO}

Ao serem questionados sobre como previnem acidentes de trabalho, os depoentes relatam o uso dos EPI's oferecidos pela instituição, além de citarem os isolamentos respiratórios de pacientes:

Luvas, máscaras, óculos e avental é ... geralmente o que utiliza aqui é isso, só (E2).

[...] A gente usa eh... os equipamentos de proteção individual né! Que vai ser a capa, a luva, a máscara, o gorro né! Quando a gente vai ter contato com esses pacientes e no isolamento têm aqueles pacientes também tem indicação da gente usar a máscara N95 né! Que é o caso, no caso os pacientes de HIN1 e os pacientes de meningite que a transmissão das doenças são aéreas $[\ldots]$ (E3).

Faço uso dos EPl's né! Necessários ao abordar qualquer paciente [...] (E5).

Em relação aos riscos biológicos sempre utilizo, trato todos os pacientes aqui como isolamento de contato né! Sempre vou com os EPI's, máscara, capa para os cuidados $[\ldots](E 7)$.

Prevenção de acidente, assim a prevenção ela é universal, a gente precisa de equipamentos de proteção individual [...] (E8).

Os EPl's são fundamentais para a prevenção, pois os mesmos são destinados a garantir a integridade física e a saúde dos profissionais, contudo é necessário que os mesmos sejam produtos de uma qualidade comprovada e recebam aprovação do Ministério do Trabalho, assim estando disponível para o uso ${ }^{18}$.

Apesar de conhecidos pelos profissionais de saúde, os EPl's nem sempre são empregados em todos os procedimentos realizados por estes. $O$ não uso do EPI, muitas vezes, é justificado por sua falta na instituição de saúde, a sobrecarga de trabalho aliada ao tempo curto para realização das atividades ou até mesmo pelo desconhecimento das medidas de biossegurança ${ }^{19}$.

Emergiu dos discursos algumas estratégias para evitar as Lesões por Esforço Repetitivo e as Doenças Osteoarticulares Relacionadas ao Trabalho (LER/ DORT), que são consequências da exposição aos riscos ergonômicos, como medidas de autoproteção conforme as seguintes declarações:

[...] E a questão dá $L E R / D O R T$ né, que são lesões causadas... EHHH principalmente ortopédicas é utilizar nas suas atividades posturas, posições corretas diante dos seus procedimentos, tipo: Banho no leito $\mathrm{EHHH}$ ... Aferição de P.A (E 1).

[...] Quanto ao acidente de trabalho que as vezes está relacionado a postura, você pode ter um problema ergonômico né! de trabalho né! [...] você desenvolve problemas articulares de artrite, artrose né! Principalmente de esforço repetitivo, as vezes diluição de medicação, escreve bastante, então você está submetido a doenças ocupacionais por esforço repetitivo né! [...] (E 4).

[...] A gente procura também ter uma postura pra mobilização de pacientes, uma postura até pra gente se sentar, pra gente garantir o desenvolvimento das atividades, procurar evitar um dano maior né! [...] (E6).

[...] Ah e com relação as doenças as DORT's mesmo eu não faço certos procedimento, não pego peso, por que eu já tenho duas hérnias de disco, uma cervical uma torácica, já é recomendação médica mesmo pra evitar certos procedimentos aqui, principalmente 
levantamento de peso (E7).

As LER/DORT são patologias que danificam o sistema músculo esquelético, sendo resultantes do uso exagerado das estruturas anatômicas com a respectiva ausência de um período para a sua recuperação, podendo causar um problema funcional temporário ou até mesmo permanente para os profissionais acometidos, isso dependerá do grau de estágio desta patologia ${ }^{20}$.

Dentre os profissionais estudados, a literatura destaca os trabalhadores da saúde como um grupo de grande risco para o desenvolvimento de LER/ DORT. De maneira especial, os profissionais da enfermagem são os que concentram o maior número de casos e representam os que mais estão expostos aos riscos advindos de sua profissão, ganhando, assim, um destaque em diversos estudos na área da saúde ocupacional ${ }^{21}$.

Através das suas explanações foi possível inferir que a percepção quantos aos riscos ocupacionais estão bem fortificadas, onde os profissionais citam e exemplificam com certa propriedade sobre o assunto, situação que é fundamental e enriquecedora para a empresa, a qual conta com profissionais que teoricamente sabem discernir os eventos que surgem no seu ambiente de trabalho.

\section{CONCLUSÃO}

Através deste estudo, observou-se que os participantes do estudo souberam sinalizar a existência de riscos ocupacionais, mencionando experiências vividas no ambiente de trabalho. Os mesmos deram maior ênfase aos riscos biológicos, não citando os riscos químicos e físicos que fazem parte dos riscos ocupacionais das clínicas médica e cirúrgica. Ao relatarem formas de prevenção de acidentes o uso de EPI's e adoção de posturas adequadas no campo de trabalho, não foram citadas comportamentos quanto a higienização das mãos, que faz parte das medidas de precaução padrão, entre outras.

O foco dos entrevistados, quanto aos riscos ocupacionais é o risco biológico e, consequentemente, o uso de EPI para este risco é a medida de prevenção mais utilizada. Portanto, conclui-se que há a necessidade da educação permanente a respeito de todos os riscos ocupacionais existentes em seu ambiente de trabalho, bem como a sensibilização da instituição quanto as dificuldades vivenciadas por esses profissionais relacionadas à sobrecarga de trabalho e recursos materiais.

\section{REFERÊNCIAS}

1. Silva EJ, Lima MG, Marziale MHP. O conceito de risco e os seus efeitos simbólicos nos acidentes com instrumentos perfurocortantes. Rev. Bras. Enferm. 2012;65(5):809-14. doi: 10.1590/S003471672012000500014

2. Areosa J. Riscos ocupacionais da imagiologia: estudo de caso num hospital português. Tempo soc. 2011 ;23(2):297-318. doi: 10.1590/S010320702011000200012

3. Rodrigues ML, Malheiros TF, Fernandes V, Darós TD. A percepção ambiental como instrumento de apoio na gestão e na formulação de políticas públicas ambientais. Saúde soc. 2012 ;21 (suppl.3):96-1 10. doi: 10.1590/S010412902012000700009

4. Duarte NS, Mauro MYC. Análise dos fatores de riscos ocupacionais do trabalho de enfermagem sob a ótica dos enfermeiros. Rev. bras. saúde ocup. 2010;35(1 21 ):157-167. doi: 10.1590/S030376572010000100017

5. Espindola MCG, Fontana RTeresinha. Riscos ocupacionais e mecanismos de autocuidado do trabalhador de um centro de material e esterilização. Rev. Gaúcha Enferm. 2012;33(1):116-123. doi: 10.1590/S198314472012000100016

6. Ribeiro RP, Martins JT, Marziale MHP, Robazzi MLCC. O adoecer pelo trabalho na enfermagem: uma revisão integrativa. Rev. esc. enferm. USP. 2012 ;46(2):495-504. doi: 10.1590/S008062342012000200031 
7. Silva CDL, Pinto WM. Riscos ocupacionais no ambiente hospitalar: fatores que favorecem a sua ocorrência na equipe de enfermagem. Rev. Saúde Coletiva em Debate. 2012;2(1):62-29

8. Brasil. Ministério do Trabalho e Previdência Social. Portaria $n^{\circ}$ 485, de 11 de Novembro de 2005. NR 32 - Segurança e Saúde no Trabalho em Serviços de Saúde. 2016

9. Lakatos EM; Marconi MA. Fundamentos de metodologia científica: Técnicas de pesquisa. 7st ed. São Paulo: Atlas; 2010.

10. Fontanella BJB, Ricas J, Turato ER. Amostragem por saturação em pesquisas qualitativas em saúde: contribuições teóricas. Cad. Saúde Pública. 2008;24(1):17-27. doi: 10.1590/S0102$311 \times 2008000100003$

11. Silva TR, Rocha AS, Ayres JÁ, Juliani CMCM. Acidente com material perfurocortante entre profissionais de enfermagem de um hospital universitário. Rev. Gaúcha Enferm. 2010;31(4):615-622. doi: 10.1590/S198314472010000400002

12. Miranda FMD et al. Uma contribuição a saúde dos trabalhadores: Um guia sobre exposição aos fluídos biológicos. Rev. esc. enferm. USP. 2011 ;45(4):1018-1022. doi: 10.1590/S008062342011000400033

13. Moura JPinto et al. A colonização dos profissionais de enfermagem por Staphylococcus aureus. Rev. Latino-Am. Enfermagem, Ribeirão Preto. $2011 ; 19(2): 325-331$.

14. Damasceno AP, Pereira MS, Souza ACS, Tipple AFV, Prado MA. Acidentes ocupacionais com material biológico: a percepção do profissional acidentado. Rev. bras. Enferm. 2006;59(1):72-77. doi: 10.1590/S0034-71672006000100014

15. Brasil. Ministério do Trabalho e Previdência Social. Portaria MTE n. ${ }^{\circ}$ 505, de 16 de abril de 2015. NR 6 - Equipamento de proteção individual. 2015

16. Schmoeller Roseli et al . Cargas de trabalho e condições de trabalho da enfermagem: revisão integrativa. Rev. Gaúcha Enferm. 2011 ;32(2):368377. doi: $10.1590 /$ S1983-14472011000200022

17. Brasil. Ministério do Trabalho e Previdência Social. Portaria SIT n. ${ }^{\circ} 13$, de 21 de junho de 2007. NR 17 - Ergonomia. 2015

18. Hirata MH. Manual de biossegurança. 2 ed. Barueri: Manole, 2012. P. 356

19. Neves HCC et. al. Segurança dos trabalhadores de enfermagem e fatores determinantes para adesão aos equipamentos de proteção individual. Rev. Latino-Am. Enfermagem. 2011 ;19(2):[8telas]. doi: 10.1590/S010411692011000200018

20. Silva EF; Oliveira KKM; Zambroni de Souza PC. Saúde mental do trabalhador: o assédio moral praticado contra trabalhadores com LER/DORT. Rev. bras. saúde ocup. 2011 ; 36(1 23):56-70. doi: $10.1590 /$ S0303-76572011000100006

21. Magnago TSBS, Lisboa MTL, Griep RH, Kirchhof ALC, Guido LA. Aspectos psicossociais do trabalho e distúrbio musculoesquelético em trabalhadores de enfermagem. Revista Latinoam Enferm. 2010;18(3):429-35. doi: 10.1590/S010411692010000300019 